\title{
La reacción del poder ante los estímulos informativos: el síndrome $B$ y el efecto I
}

\author{
Dr. José Manuel de Pablos Coello \\ Catedrático de Periodismo \\ Universidad de La Laguna (Tenerife, Canarias)
}

El profesor de Pablos aporta numerosos casos que demuestran una reacción del poder ante determinados mensajes periodísticos que puedan afectar negativamente su imagen. A esto denomina Síndrome B. Pero también otros poderes, en esta ocasión ilegales, como organizaciones terroristas o traficantes de droga, pueden reaccionar, a su manera ante mensajes contrarios a sus fines. Este es el Efecto I.

$\mathrm{V}$

amos a plantear aquí la hipótesis según la cual el poder, cuando le afecta, reacciona a las críticas y comentarios peyorativos o simplemente noticias aparecidas en prensa. Responde así al contenido de textos que ponen en duda la capacidad del poder cuestionado, cuya imagen sale deteriorada o, más sencillo aún, da a entender a sus fieles o seguidores que su condición de hegemón empieza a dejar de ser tal; este extremo invitaría a otros a situarse en la posición de autoridad ocupada hasta entonces por el poder debilitado desde los textos críticos.

Si se fijan, hablamos de una cuestión de moral: el poder -del tipo que sea, lícito o ilícito- no va a reconocer su mala actuación, pero una nota en prensa, radio o unas imágenes en televisión lo pueden poner en evidencia y ha de reaccionar para seguir en su mismo estado de ejerciente del poder.

Pierre Sané(1), secretario general de Amnistía Internacional, lo explica muy bien cuando dice: «Ningún gobierno reconocería abiertamente estar actuando en contra de los principios aceptados por ellos (...) Ningún gobierno acepta estar comportándose de modo inmoral, aunque lo haga. Lo ocultan (...) Nuestra estrategia es revelarlo en la prensa. Tenemos esa posibilidad y la usamos. Sin la prensa y la opinión pública sería peor (...)». Se trata de avergonzarlos, le comenta la periodista al representante de A. I.; éste contesta: «Exacto, se puede hacer y hay

(1) «Pierre Sané / La conciencia de la Tierra», entrevista de Soledad Alameda al secretario general de Amnistía Internacional; dominical de El País, 22 de marzo de 1998, número 1.121, pp. 24 a 30. 
que hacerlo. Y por eso trabajamos tan cerca de los medios de comunicación, porque ellos son nuestra herramienta para avergonzarlos públicamente»(2).

La importancia del síndrome B -B de Buckingham; ya explicaremos la propuesta nominativa- está en que el periodista o el usuario de los medios de comunicación (tal es el caso de A.I. y de tantos grupos de minorías, ecologistas, ongs, etc.) ha de calcular la respuesta del poder que cuestiona o provoca, aunque sea de forma indirecta, taimada o subliminal. Esto, porque existen poderes fuera de la ley, cuya réplica provocada por el producto periodístico puede estar igualmente al margen de la legalidad: en este último tipo de casos no hay duda de que habrá una seria responsabilidad del informador. Esto será así sobre todo cuando el blanco de la reacción inducida es una tercera persona y no el autor de la información causante de la reacción al estímulo informativo originado.

Veamos algunos ejemplos donde se pone claramente de manifiesto algún caso de síndrome de Buckingham.

La cara prueba del ADN

A) En el pequeño pueblo francés de Pleine-Fougères, un delincuente violó a una niña inglesa de 13 años mientras se encontraba en la localidad con una excursión de su colegio. Sucedió el 18 de julio de 1996.

Desde entonces y hasta el año siguiente, poco avanzaba la investigación policial, lo que daba pie a la crítica continúa de la prensa inglesa sensacionalista; ésta tenía en sus manos un caso perfecto de morbo y nacionalismo en el que insistir y profundizar de forma reaccionaria y populista, dos maneras que favorecen la venta de ejemplares, que es siempre de lo que se trata en este tipo de ejercicio diabólico.

Recordemos que el morbo y el nacionalismo son dos de los ingredientes de la prensa amarilla, a la vez que la actuación reaccionaria y populista son dos de las herramientas comunicativas de los periódicos sensacionalistas.

En 1997 se cambió de fiscal instructor del caso y éste, encarnado en poder -un poder del estado- reaccionó a los comentarios impresos que dejaban en mal lugar la imagen de la justicia francesa. «Así, el nuevo instructor ha adoptado esta decisión [la de hacer la prueba del $\mathrm{ADN}$ a todos los varones de la población en edades comprendidas entre los 15 y los 35 años] cuando los hilos políticos comenzaban a moverse y a la vista de algunas descalificaciones vertidas por algunos tabloides británicos contra la investigación judicial francesa» ${ }^{(3)}$.

Es fácil entender que la decisión del fiscal no es sólo suya. Ya dice la crónica periodística ${ }^{(4)}$ que se adopta la decisión «cuando los hilos políticos comenzaban a moverse», de donde cabe desprenderse que el poder político, igualmente

(2) Ib., p. 30.
(3) El Pais, 7.9.97, p. 15 / Domingo, «Con el ADN en la boca».

(4) La firma José Luis Barbería, corresponsal en París. 
puesto en evidencia desde el país vecino, aporta su colaboración para el cese de las críticas en papel prensa. De lo contrario sería descabellado pensar que el juzgado de un pequeño pueblo (francés o del país que fuere) pueda disponer de presupuesto normal suficiente para el gasto que supone la localización de las impostas del ADN de unos vecinos: cada una cuesta entre 25.000 y 37.000 pesetas, en todo caso por persona analizada.

En conclusión de este primer episodio estudiado, tenemos:

$\left.1^{\circ}\right)$ Un suceso horrible y despiadado, de los que provocan mayor alarma social, es tratado desconsideradamente y con gran énfasis por la prensa amarilla inglesa, que explota el suceso y descalifica al otro, que en este caso es la judicatura y la policía francesas. Dada toda la información recopilada y tras la exigencia de resultados que cierren el caso, la prensa amarilla insiste y acelera sus críticas, en un juego incesable e insistente, que aumenta o mantiene sus altas ventas, siempre finalidad del sensacionalismo.

$\left.2^{\circ}\right)$ El poder afectado por la extremada crítica empieza a quedar en evidencia y su imagen, espejo de todas sus cualidades, comienza a deteriorarse; el poder lamenta lo que le sucede, por lo mucho que cuesta fabricarse una imagen positiva y aceptada por la población, por los medios.

$3^{\circ}$ ) El poder reacciona. Lo hace el judicial y el político; el policial tiene menos posibilidades, pues disponer de mayor o menor número de recursos no depende de ellos sino del poder político. Éste pone todos los medios para encontrar una solución al caso, que no es otra que encontrar al culpable, hacerle que confiese, llevarlo al juzgado y condenarlo. Esta reacción puede ser de tal envergadura que sorprenda a los lectores que han seguido el caso por los periódicos, vistos los extremos de tal respuesta positiva y capaz de acallar las críticas, al menos temporalmente. Ya no podrán decir que nada hacen, que se han desentendido del problema. Algo habrá conseguido el poder criticado.

$\left.4^{\circ}\right)$ El caso entra en vías (aparentes) de solución: la prensa ha de acoger de forma satisfactoria -no tiene entonces otro remedio- la nueva situación cuando el nuevo rumbo del problema parece normalizar las cosas o se vislumbre una posibilidad de solución.

No ocurrirá tal cosa cuando el poder es un poder no legal o sus integrantes sean proscritos y su reacción signifique agravar un estado de cosas; en tal caso, la postura del periodista será puesta en evidencia, con las responsabilidades penales o policiales que no llegan a alcanzar a los que están más allá de los límites sociales de lo permitido, fuera de la ley; en nuestro caso, también más allá de los límites del periodismo, fuera del periodismo.

Hemos visto cómo ante una situación de crítica y de deterioro de la imagen pública, el poder reacciona y lo hace aparentemente a favor de la teórica solución del problema planteado: es una reacción positiva al estímulo informativo. 
La familia iraní que iba a ser expulsada

B) Veamos otro caso: A primeros de septiembre de 1997, una familia católica iraní residente en Málaga, acogida por una organización no gubernamental, hace saber a la opinión pública española que el Ministerio del Interior les ha dado un plazo de diez días para que abandonen España, después de denegarles el asilo político solicitado. Los periódicos han narrado que el padre ha estado en la cárcel en Irán por sus creencias religiosas y que sus hijos están ya matriculados en un colegio malagueño: se trata de una familia normal y el Ministerio del Interior los echa de España.

La imagen del gobierno sale malparada, puesta en evidencia; no es soportable. El poder ha de reponerse de esta lesión de su imagen y hacerlo pronto. Así(5), encontramos la noticia que se adapta a un síndrome de Buckingham: «Interior dará la residencia a la familia católica iraní con cinco niños que iba a ser expulsada».

El texto empieza así: «La respuesta ha sido inmediata ${ }^{(6)}$. Un día después...».

Vemos, entonces, cómo se presenta y desarrolla este nuevo caso de síndrome B:

$\left.1^{\circ}\right)$ Una familia iraní hace saber que va a ser expulsada de España. El hecho de que sean católicos da mayor gravedad al caso, y más cuando aseguran que el padre ha estado en la cárcel de Irán por ese motivo. El Ministerio del Interior y el propio gobierno, en este caso integrado por católicos, algunos de ellos fervientes militantes del Opus Dei no podrán soportar semejante crítica: si fuera un gobierno socialista... pero en uno católico, apostólico y romano sería demasiada incompetencia e incoherencia. La ong que actúa en el caso ha puesto en práctica la estrategia comentada por el secretario general de Amnistía Internacional reproducida al principio de este texto: informativamente ha tratado de poner en evidencia al gobierno y lo ha conseguido.

$2^{\circ}$ ) En menos de 24 horas, el poder responde y deja las cosas en su sitio, su imagen recuperada: la familia se podrá quedar en España, pero no con la figura del asilo político (para «no deteriorar esa figura secular»: demuestra el poder que sabe hacer bien las cosas, que las controla), sino con «la residencia por motivos humanitarios». A los iraníes y a la opinión pública les dará igual una figura que otra y a los lectores les parecerá bien, muy bien, que el gobierno haya tenido la sensibilidad suficiente para que este caso se resolviera tras un perfecto síndrome de Buckingham.

Entrada de ilegales en Melilla

C) Un nuevo caso: en el verano de 1997 se intensificaron las noticias publicadas referentes a la entrada ilegal de marroquíes en Melilla (plaza de

(5) El Pais, 5.9.97, p. 23 / España

(6) Éste y los demás subrayados son nuestros: forman la parte de la información que destaca el sentido de la reacción al estímulo informativo originado. 
soberanía española en la costa norteafricana). Se insiste en la prensa en el caso de niños mendigos que entran forzados por sus padres para pedir en las calles melillenses y se recoge el consejo oficial de que no se les dé dinero, para acabar así con este tipo de mendicidad. Se publica que a los pequeños que retira la policía se les lleva a un albergue y han de ir sus padres a buscarlos, con lo que se asegura que suelen ser siempre los mismos niños, los mismos padres. Ese ambiente se completa con la intervención del defensor del Pueblo, que pide «medidas de emergencia» ante la situación de los inmigrantes ilegales en Melilla ${ }^{(7)}$. El punto final de la «provocación informativa» salió publicada pocos días después de la primera información ${ }^{(8)}$ y el autor narra, con el testimonio de la Guardia Civil del paso fronterizo con Marruecos, cómo se colaban los chiquillos a la carrera.

Es más que evidente que el testimonio de los guardias civiles se puede recoger porque previamente habrán recibido la expresa y tajante instrucción de hacerlo: ningún militar de la Guardia Civil habla con un periodista sin el permiso correspondiente. Aquí tenemos, pues, una estrategia de uno de los poderes en escena (el gobierno), para originar que otro de los poderes (una institución armada) haga una intervención informativa.

Para intensificar la comunicación de este estado de cosas, se inserta una serie de fotografías e infografías para dejar más claras las deficiencias en el control, cómo la iluminación nocturna es insuficiente, en definitiva, lo sencillo que era penetrar en Melilla desde Marruecos de forma ilegal.

Como sucede en todo síndrome de Buckingham, la respuesta oficial no se hizo esperar. Pocos días después ${ }^{(9)}$, encontramos una pequeña nota datada en Melilla, sin autoría señalada, que se titula: «Los militares refuerzan la frontera [de Melilla] para impedir la entrada de inmigrantes ilegales» ${ }^{(10)}$. Dado el peso y presencia del ejército en la plaza de Melilla, no era de sorprender que fueran los militares quienes esta vez protagonizaran la reacción en un síndrome de Buckingham: «En los últimos días, soldados de todas las unidades con base en Melilla están realizando labores de apoyo a la Guardia Civil (...), porque consideramos que la situación era excepcional», concluye la nota, que vuelve a demostrar que el poder responde siempre que la situación le merezca la pena, siempre que no desee que se deteriore más su imagen ante la opinión pública.

(7) El Pais, 30.8.97, p. 18 / España

(8) El Pais, Domingo, 29.8.97

(9) Abc, 16.9.97, p. 53/Regiones.

(10) La breve nota va en una página dedicada por entero a Melilla, de ahí que en el título no haya referencia directa al lugar. Hagamos hincapié en algo más: la entrada de esas personas es ilegal, pero a ellos no se les puede aplicar semejante calificativo (ellos no son ilega es, sho su accion), ćste es un eror critcable de la actual prensa española. Por tanto, aquí, no se trata de "la en" vocabulario policial), sino de "la entrada ilegal de inmigrantes", que es una forma más respetuosa y podrá generar descrédito hacia la profesión. 
Aquí nos podríamos preguntar: ¿es que los militares desconocían la cuestión, no intervenían porque no estaban informados del aparente problema? ¿Tuvieron acaso que enterarse por la prensa para tomar una determinación que podrían haber decidido tiempo atrás? No, simplemente ha sucedido que la imagen del poder empezó a quedar lesionada, y en Melilla la idea de poder está íntimamente ligada a la figura de lo militar, de ahí la respuesta al estímulo informativo que supuso aquella serie de notas en prensa.

\section{Presos políticos en España}

D) Veamos un nuevo ejemplo de síndrome de Buckingham, que es digno de figurar aquí, sobre otros muchos que son fáciles de seguir en la prensa ${ }^{(11)}$.

La organización Amnistía Internacional, de acuerdo con la estrategia señalada por su secretario general reproducida al comienzo de este texto, en su informe de 1997 incluyó a España en la lista de países con presos políticos. La sola idea era algo escandaloso para una democracia occidental y homologada como la española. La noticia, prácticamente inadvertida por la prensa o advertida pero no publicada por aquello de la sumisión mediático-gubernamental, se refería a los jóvenes presos por insumisión al ejército de reemplazo condenado a desaparecer como tal dentro de pocos años.

Ante el hecho, el gobierno preparó con gran sorpresa general una modificación legislativa según la cual no se iría a la cárcel por insumisión y los encarcelados serían puestos en libertad.

El rápido cambio de postura del gobierno sorprendió a la opinión pública, que no se podía explicar esa modificación por sorpresa y sin aparente motivación: todo fuera por que España desapareciera del vergonzoso capítulo de países con presos políticos del informe de 1998; y se hacía a tiempo, para que los redactores del informe de Amnistía Internacional tuvieran tiempo más que suficiente de preparar la modificación adecuada.

Veamos dos últimos casos; el primero da nombre a este esquema informativo (el síndrome de Buckingham). En el segundo, el poder está fuera de la ley y el estímulo informativo se transforma en una suerte de «provocación periodística»,

(11) Ha habido muchos casos de este síndrome; sólo basta leer los diarios con cierto detenimiento para sor-

prender este fenómeno comunicativo. Algunos ejemplos recientes:
- Un periódico informa de que en una provincia del norte de España hay varios contenedores con meUn períodico informa de que en una provincia del norte de España hay varios contenedores con medicinas y alimentos para su envío a Cuba, pero no llegan a salir porque la ong que gestiona la ayuda se ha quedado sin recursos y las autoridades locales no responden a sus requisitos. Pocos días después, la nueva noticia dice que las autoridades locales se harán cargo del envío y que éste saldrá de inmediato: un caso típico de respuesta positiva a un estímulo informativo.

Se informa de que la empresa Telefónica de España S.A. trata de vender datos de sus clientes a quien los usaría como banco de datos para comercializar por correo. La noticia, tras mentís imposibles de creer, acaba siendo que la Telefonica no hara tal cosa y la empresa se ve obligada a comunicar por escrito spués de haber quedado más que probado que lo venía haciendo. 
que termina o puede acabar por originar una acción al margen igualmente de la ley y con la condena social y judicial del autor de tales textos.

Tras la muerte de Diana Spencer

E) Cuando la muerte de Diana Spencer, princesa de Gales, hubo en el mundo, pero en el Reino Unido más en particular, una oleada de histeria y devoción por el ser desaparecido.

Formalmente, Diana estaba fuera de la casa real británica tras su divorcio de Carlos de Inglaterra, por lo que el suyo tenía que ser un entierro más bien comedido, sin los faustos reales; pero, ni el público ni mucho menos la prensa amarilla inglesa iba a tolerar aquel desaire final a lady Di, así que se puso en marcha la primera de las fases de un posible síndrome de Buckingham, que se nomina precisamente por este caso, del nombre de la residencia donde se aloja el poder que aquí iba a ser provocado y tendría que reaccionar.

Los periódicos del 4.9.97 ya anunciaban lo que se iba a producir, la necesaria respuesta del poder: «La presión popular obliga a la reina a ampliar el recorrido del cortejo fúnebre en Londres» ${ }^{(12)}$; «La prensa británica critica la frialdad de la familia real durante la muerte de Diana» y «Alargan el recorrido del cortejo fúnebre ante las protestas del público» ${ }^{(13)}$. El sumario principal insistía en la 'provocación informativa', siempre merecedora de una respuesta del poder: «Advierten [los diarios británicos] que el sábado [día del entierro] [la familia real británica] puede enterrar su futuro si no cambia de actitud».

La provocación, ya en un segundo estadio [primero, alargar el recorrido] era muy concreta y de grandes proporciones, de ahí que el reto lanzado al poder fuera de gran magnitud y de respuesta urgente.

En efecto, siguiendo los titulares de los diarios indicados, encontramos:

- «La reina cambia sus planes y dirigirá un discurso a la nación / Las críticas del pueblo y la prensa por la frialdad mostrada obligan a Isabel II a tomar esta decisión» ${ }^{(14)}$.

- «La familia real británica reacciona a las críticas y dice que también sufre $~^{(15)}$. El texto de primera página aclara el síndrome de Buckingham: «La familia real británica se vio ayer forzada a rectificar. Espoleados por las críticas a la frialdad y distanciamiento mostrados» (...) «Un portavoz oficial reconoció que la reina se siente 'herida' porque su pueblo piense que no le acompaña en el dolor». En el interior (p. 4) encontramos un título semejante y el texto empieza de esta guisa: «'¡Ya era hora!'. El grito de un hombre en cola a las puertas de palacio (...)».

(12) El País, 4.9.97, p. 3 / Internacional. Los subrayados son nuestros.
(13) La Gaceta de Canarias, 4.9.97, p. 10 / Sociedad, despacho de la agencia Efe.

(14) Despacho de la agencia Efe publicado en La Gaceta de Canarias, viernes, 5.9.97, p. 19 / Sociedad.

(15) El País, 5.9.97, p. $1^{\mathrm{a}}$, con pase a las pp. 4 a 7. 
El ambiente de crítica popular tenía su fiel reflejo concreto en la prensa, amarilla o no. The Mirror solicitaba ese discurso de la reina: «Háblenos, señora» y el conservador The Times, prudente, ponía su aportación para que apareciera el síndrome de Buckingham lógico: «Hay momentos en la historia de cada institución en los que sus reglas no importan menos que su raison d'etre». El diario The Sun, campeón del sensacionalismo británico, iba en búsqueda de un más completo síndrome de Buckingham: «¿Dónde está la reina? ¿Dónde su bandera?». La reina seguía sus vacaciones de verano en el palacio de Balmoral; las tuvo que interrumpir para acudir al funeral.

- «Isabel II: 'Diana era un ser excepcional / Los británicos pudieron dar el pésame en persona a la familia real» ${ }^{(16)}$

- Bajo el título anterior, leemos: «La reina de Inglaterra rompió ayer más de una tradición para acercarse a su dolorido pueblo (...) La ruptura de esa tradición se presentó en forma de ruptura del protocolo de disciplina al que son muy fieles los miembros de la familia Windsor, reinante en el Reino Unido». Esas novedades, que se ajustan a la perfección al síndrome de Buckingham, fueron que la reina realizó un mensaje personal de tres minutos «en lugar de grabarlo con anticipación, como no lo ha hecho desde 1959». El corresponsal concluye: «Otro elemento que dio carácter extraordinario a su mensaje fue el hecho de que [la reina] jamás había empleado expresiones tan personales como aquella admisión ayer de que hablaba a sus súbditos no sólo como reina sino también como abuela y que lo hacía 'de corazón'».

El asunto de la bandera real fue otro detalle que subraya el síndrome de Buckingham que definimos. Dice el protocolo y la tradición de los Windsor que la bandera real ondeará en lo más alto del mástil del palacio de Buckingham cuando Isabel II está en Londres: es su icono presencial. No habrá bandera real en el asta cuando la soberana se encuentre ausente de palacio.

En consecuencia con lo anterior, el mástil de lo más alto de Buckingham estaba sin bandera en las vísperas del entierro de Diana, mientras la reina seguía en Balmoral y el público hacía once horas de cola para firmar en alguno de los 43 libros de condolencia establecidos para ello. Éste de la ausencia de bandera a media asta en lo alto del palacio fue otro de los motivos de irritación popular, tan bien recogido por la prensa amarilla, como hemos visto que hizo The Sun. Así, el corresponsal de El País ${ }^{(17)}$ escribía: «El duque de York y Eduardo habrían acudido a la capilla privada de St. James ${ }^{(18)}$ para rendir tributo a Diana en el primer gesto del género por parte de Buckingham, donde el mástil permanece desnudo a pesar del clamor popular para que los Windsor expresen su duelo (...)».

(16) El País, sábado, 6.9.97, p. 4 / Internacional, crónica de Juan Carlos Gumucio, corresponsal en Londres.

(17) El Pais, sabado, viernes, 5.997, p. 4 / Internacional.

(18) El palacio donde estaba Diana de cuerpo presente. 
$\mathrm{A} 1$ regreso de Isabel II a Londres, el mástil de Buckingham lució la enseña real, indicativa de que la reina ya estaba en su palacio. El sábado, cuando la reina saliera para ir al funeral, esa enseña se tendría que arriar y volver a dejar el mástil sin bandera alguna, pero hizo acto de presencia la materialización del síndrome de Buckingham.

Veamos las noticias de aquel día:

- «En el momento en que salía la reina de su palacio de Buckingham, se arrió la enseña real y se izó a media asta la bandera británica, algo que no ocurre ni con la muerte de los reyes, pero reclamado insistentemente por los ciudadanos, que acogieron con aplauso este gesto real $\gg^{(19)}$.

En conclusión, tenemos de nuevo:

$1^{\circ}$ ) Hay ocasiones en que la prensa (amarilla o no) recoge u origina críticas o informaciones sobre determinadas cuestiones, situaciones o sucesos, cuya mera presentación a los lectores pone en evidencia la administración o gestión de un tipo cualquiera de poder o su apego o despego de los sentimientos populares. En todo caso, el hecho expuesto origina un comienzo de erosión en la imagen del poder criticado directa o indirectamente y esa crítica, de manera subliminal o no, cala en la opinión pública y, naturalmente, entre quienes ocupan el poder cuestionado.

$2^{\circ}$ ) La misma solución al caso, que no es otra que cortar el estado de cosas, será poner pronto remedio a la situación planteada. Para ello, el poder actúa en el sentido de que deja ver que hace algo que pone o facilite que se ponga punto final a las críticas, sean presentadas como tales críticas o sean meras informaciones con una denuncia comunicativa adherida a ella, que habrá actuado como estímulo informativo al que siempre suele seguir una respuesta, conformando el teorizado aquí síndrome de Buckingham.

$3^{\circ}$ ) La aparición en el espacio mediático de la nueva originada desde el poder acaba con la situación expuesta, como algo donde se daban anomalías, con lo cual se logra apaciguar el descontento del público receptor de los mensajes mediáticos.

$4^{\circ}$ ) A todo este proceso comunicativo lo llamamos síndrome de Buckingham, por haberse desarrollado paso a paso, en sus diversas etapas, entre la familia real británica, con motivo de los hechos del verano de 1997, y haber sido el palacio de ese nombre donde transcurrió el hecho tal vez significativo de ruptura de una vieja tradición real, como forma de responder al estímulo informativo originado y publicado.

Este tipo de síndrome comunicativo es anterior a 1997, claro está, y se habrá manifestado a todo lo largo de la historia de la comunicación periodística, cuando ha habido una prensa en libertad capaz de juzgar cualquiera de los poderes de su

(19) La Gaceta de Canarias, domingo, 7.9.97, p. 13 / Sociedad, en crónica de agencias. 
entorno, crítica que será más intensa cuando la prensa hace amarillismo como forma de incremento de sus ventas. Es igualmente cierto que lo sucedido en Londres sería muy difícil que ocurriera en Madrid en un caso semejante. Lo que entraría en juego en España no sería un síndrome $\mathrm{B}$, sino un síndrome $\mathrm{S}$, de sumisión, o sea, de silencio también; no de provocación o estímulo a cierto tipo de poder, aunque sea virtual, sino de pasividad y silencio, consensuados todos los medios para obviar extremos informativos de indudable interés público.

A lo largo de este estudio y hasta aquí hemos visto varios ejemplos, sucedidos en Inglaterra, Francia y España, todos los cuales tenían algo en común: el poder que respondía era un poder legal (la casa real, la judicatura, el gobierno por medio de uno de sus ministerios o el ejército).

La respuesta positiva y apaciguadora de cualquier tipo de poder a un estímulo informativo, de alguna manera es un contratiempo que le sale al paso al poder y éste se ve obligado a actuar en consecuencia, forzado por la situación creada siempre por sorpresa y en contra de su voluntad.

Es un contratiempo completo, que podía haberse evitado si el poder hubiera evitado motu proprio el estado de cosas originado por una torpeza, hábilmente manejada por los media, serios o amarillos.

Por esta razón, el síndrome B tiene algo de erosión de la soberanía del poder puesto en evidencia: se gana o recupera la imagen que se estaba perdiendo a cambio de un poco de soberanía, que es moneda más fácil de perder en manos de terceros o desde los emisores mediáticos. El síndrome B es un fortalecedor de la democracia civil.

Este extremo tiene sus excepciones, cuando al poder no le preocupa su imagen o en presencia de lealtades inquebrantables, ausencia de libertad de expresión o en un estado real de sumisión o ultraveneración hacia algún tipo de poder, que de criticable pasa a adulado. Un caso muy gráfico de este otro aspecto del síndrome B lo encontramos en una noticia fechada en Pekín ${ }^{(20)}$. Según esta crónica, la liberación de Wang Dan, líder estudiantil del levantamiento democrático de Tianamen, se hacía esperar y éste seguía en la cárcel, a pesar de que estaba decidida su liberación por el gobierno; tal cosa sucedía porque «sólo el interés que despierta en los medios de comunicación ha podido echar para atrás la decisión de las autoridades, que no quieren parecer forzadas a actuar por ningún otro país» ${ }^{(21)}$

'Desde el poder no se quieren ver forzados' es uno de los extremos de un síndrome B para cualquier tipo de situación hegemónica, preocupado ese poder por su imagen, que evidentemente no parece que fuera el tema prioritario para el

(20) «El líder de los estudiantes de Tianamen cree que su liberación es imposible / Pekín acusa a los periodistas del retraso de su excarcelación». Abc, 4 de abril de 1998, pág. 38 / Internacional, crónica de su corresdel retraso do su cxca

(21) Texto tomado de la entradilla de la crónica citada. 
poder cuando éste es un gobierno dictatorial. Sigue la crónica: «Es una cuestión de principios que China suele llevar a rajatabla. En cuestiones de 'soberanía', Pekín es tremendamente sensible y el concepto chino de 'no perder la cara' podría haber llevado a retrasar una situación que algunos analistas dan por tomada» ${ }^{(22)}$. O sea, responder de manera natural, prudente, a un síndrome comunicativo como el apuntado se califica desde el poder en el caso aquí analizado ahora como 'cuestión de principios', sin percatarse los responsables chinos de que mientras más dure una situación como la estudiada, para los medios ésta tendrá mayor interés y su desenlace ganará peso específico a medida que pasen los días sin ofrecer la solución anunciada oficiosamente. Esta salida no puede ser otra que la natural culminación del síndrome B, la respuesta afirmativa al estímulo lanzado desde los medios de comunicación de masas. Lo contrario significará el fomento y cultivo de un peligroso quiste en el propio seno del poder o grupo mediáticamente cuestionado.

\section{El efecto I}

La nueva cuestión que planteamos es la que sigue: ¿Qué sucede cuando el poder retado desde un medio, directa o indirectamente, es una fuerza al margen de la ley? Sucederá exactamente lo mismo: un síndrome de Buckingham canónico tal y como hemos visto hasta aquí, con la diferencia de que su reacción se hará también fuera de la ley y su resultado igual, sólo que no lo llamaremos síndrome de Buckingham -que siempre tiene un cariz positivo- sino efecto I, y el lector entenderá la razón del nombre.

El efecto I será tal cuando se materialice la reacción del poder provocado o al que se le han dado sugerencias subliminales desde las páginas de un periódico. En plena 'guerra digital' española de los 90 (título de un libro de Martínez Soler), el en un principio diario emblemático de la transición hacia la democracia, El País, produjo una de estas sugerencias o información-denuncia, según parece demostrado, basado en una no-realidad. Así, a la semana siguiente de la firma de un acuerdo entre el Grupo Zeta con varios clubs de fútbol para ceder estos sus derechos televisuales a Antena $3 \mathrm{TV}$, El País insertó la escandalosa 'noticia' ${ }^{(23)}$ que relacionaba a uno de los directivos de Zeta con los interrogatorios que acabaron con la vida de un supuesto etarra en comisaría, siendo el denunciado por el diario de Prisa comisario de aquel centro policial.

Ese mismo día, un grupo de profesionales de Antena $3 T V^{(24)}$ se dirigió al empresario dueño de El País y lo invitaron a reflexionar con estas palabras: «Lo

(22) Fue liberado a la semana siguiente.

(23) Martínez Soler (La guerra digital, p. 105) recuerda: 'La información de El Pais (...) se publicó sin firma (algo habitual cuando ningún redactor quería asumir el coste ético y profesional de unir su nombre a una (algo habitual cuando ningún redactor quería asumir el coste ético y profesional de unir su nombre a una
noticia sesgada o no veraz)'.

(24) noticia sesgada o no veraz)

Carnicero, entre otros periodistas. 
que publica hoy el diario El País bajo el título 'Un ex comisario negocia el fútbol para Antena 3' va demasiado lejos. En defensa de unos intereses empresariales no se puede echar a un hombre en manos de ETA, ni aún con la verdad por delante. En este caso, con una gravísima falsedad. Joaquín Domingo Martorell [nombre del ex comisario, directivo de Antena $3 \mathrm{TV}$ ] no conoció a José Arregui físicamente [la persona muerta tras nueve días de "interrogatorio" policial]. Por tanto, no pudo interrogarlo. Simplemente intervino como perito en el juicio oral seguido contra los policías acusados». Martínez Soler, en su libro citado (p. 106) tilda ese reportaje de El País como 'información tan interesada' (...) 'que tanto daño hizo al prestigio del primer diario de la democracia (...)'.

Un poder fuera de la ley (una banda terrorista o de narcotraficantes; un grupo mafioso) dará su particular respuesta, porque el efecto I, como el síndrome de Buckingham, parece una ley universal. Lo que sucederá -como ya indicamos- en el caso del poder situado fuera de la ley es que su respuesta también se va a poner fuera de la ley y aquí aparece una muy seria responsabilidad del periodista que lanza esta modalidad de provocación informativa al poder o fuerza ilegal, de ahí el reproche que hicieron al empresario Polanco los profesionales de Antena $3 \mathrm{TV}$.

Veamos un supuesto: un periodista hispano publica una serie de reportajes en los que dice (se demuestre o no) que en una ciudad determinada actúa una célula de los grupos paramilitares y cita lugares y nombres de esos sitios y de los personajes que los regentan o animan esa actividad ¿Qué le queda por hacer a un individuo que lidere un cártel de la droga o sea el jefe de un grupo de traficantes de sustancias narcóticas? Podrá suceder dos cosas:

$\left.1^{\circ}\right)$ Que no se entere de lo publicado y tampoco alguien de su entorno, con lo cual el mensaje no habrá llegado a su destinatario natural con posibilidad de responder a la 'provocación informativa'. Será difícil que tal cosa suceda.

$2^{\circ}$ ) Que al narcotraficante o a alguien de su corte le llegue el mensaje; sucederá sobre todo si la fuerza o poder fuera de la ley es una organización de masas o con simpatizantes informativos, tal sería el caso de una banda terrorista o de un grupo guerrillero, aunque se encuentra en terrenos donde no se consigan periódicos.

A partir del segundo punto pueden suceder dos supuestos:

a) El sujeto fuera de la ley no toma decisión alguna y deja pasar la información-denuncia.

b) Se limita a dar una simple orden a alguno de sus sicarios; en un caso con la gravedad del que nos ocupa no podría ser otra que mandar matar a los supuestos paramilitares, simpatizantes o informadores: si se han aventurado en su territorio no puede ser sino para colaborar en su captura o liquidación. En tales casos, ¿habrá mucha meditación frente a la suerte que deban correr tales 'enemigos'?

La responsabilidad del periodista en ese momento es muy grave, porque todo informador debe saber cómo se desarrolla un efecto I, llámese como se le llame o aunque no reciba nombre alguno: lo ha de intuir, como lo interpretaron los 
periodistas de Antena $3 T V$. Es elemental, lo indica la experiencia más breve, que todo tipo de poder siempre responde a cualquier tipo de provocación informativa, aunque el mensaje emitido o impreso no lleve el formato de denuncia clásica. Igualmente básico es que todo informador ha de calcular los efectos de sus mensajes, como sucede por ejemplo en periodismo científico. El rigor debido en el periodismo científico se debería extender como norma a todos los periodistas, incluidos los de sucesos y los de deportes.

En el supuesto americano, los defensores del periodista cuestionado tras una seria manifestación del efecto I dirán siempre lo mismo: "Al narcotraficante $\mathrm{X}$, con toda la red de informadores que tiene, no se le puede pasar por alto que aquel bar, aquella empresa... era una tapadera. Tenía toda la apariencia de ser otra cosa, diferente a la que decía ser, así que tiene muy poco valor decir que se enteró por la prensa, por nuestra información».

Eso puede ser así. El traficante o el terrorista puede tener conocimiento de que alguien es un enemigo o un informador del enemigo, pero lo puede tener bajo vigilancia, de alguna manera informativamente controlado, de forma que deja de ser un peligro potencial e incluso puede que lo utilice para pasar falsos mensajes al destinatario, de aprovecharse de su presencia en el lugar. Se podrá dar el caso de que en el seno del grupo o banda haya polémica acerca de la conveniencia de actuar sobre ese lugar o sobre determinadas personas relacionadas con ese sitio, pero la estrategia de quien da las órdenes últimas le aconseje prudencia o no gastar las energías en ese objetivo. Igualmente es posible que esa sede y esos individuos fueran desconocidos. En todo caso, desde que el asunto aparece en un medio, se desencadenará una serie de circunstancias que alterarán radicalmente la situación y así se pone en marcha un síndrome de Buckingham negativo o efecto I: el poder ha de responder; si no lo hace pierde imagen, se le diluye parte de su hegemonía, que en una banda fuera de la ley se puede transformar en la toma de la dirección por una de las facciones. A los jefes del cártel o de la banda no les queda nada más que dos opciones:

I) Dar la orden de que acaben con los peligrosos individuos señalados y marcados por el periodista;

II) Dar una respuesta si la situación creada ha sido originada por los periódicos en su conjunto. Cualquier cosa, antes de perder su papel de hegemón dentro del grupo ilegal.

Responsabilidad mediática

Aquí estriba, insistimos, la grave responsabilidad del periodista o de los medios en general. Aunque el sujeto situado fuera de la ley directa o indirectamente provocado informativamente conociera las actividades del grupo o persona señalada por el periodista, a partir de su publicación el asunto será de dominio

(25) El País, 18 de abril de 1996, la 'noticia', y el 19 de abril de 1996, la réplica. 
público: gana otra dimensión y deja de estar controlado. Su inhibición sólo se podría interpretar como incapacidad para seguir al frente del cártel o de la banda armada, del grupo ilegal de que se trate, ante sus correligionarios, subordinados y simpatizantes en la sociedad.

Para comprobar la consecuencia de un síndrome de Buckingham negativo o efecto I cuando se trata de gente fuera de la ley, tenemos un caso terminal ${ }^{(26)}$ de publicación en la revista española Interviú (campeona de prensa amarilla y, por ello, con la gran tirada [y enorme negocio] que supone el sensacionalismo duro). En el año 1979 Interviú publicó una serie de reportajes firmados por Xavier Vinader y realizados a partir de las declaraciones de un ex policía (¿cobrando por ellas?). Se refería a la existencia de un grupo antiterrorista formado por ciudadanos, con sede en una serie de bares de Baracaldo (País Vasco), donde aparentemente operaba ese supuesto grupo. Poco después de la publicación, la banda terrorista asesinó a una de las personas citadas en el texto de Vinader: era lógico que el poder terrorista respondiera en un clásico síndrome de respuesta del poder clandestino o fuerza ilegal puesta en evidencia.

La prensa clásica criticó duramente a la revista, de modo que su empresa editora se vio impulsada a publicar en los diarios de mayor tirada, nacionales y provinciales, un anuncio ${ }^{(27)}$ que no tiene desperdicio y viene a demostrar el alto interés documental de las hemerotecas: es una muestra del cinismo amarillo de un medio sorprendido en el grave pecado de prensa amarilla militante y rotunda. Algunas de sus líneas dicen: «De una manera brutal, con un tono de incitación a comportamientos propios de guerra civil -nos trae recuerdos de las tristes fechas que antecedieron al 18 de julio de $1936^{(28)}$ - cierta prensa española nos hace prácticamente responsables, y casi coautores, de la muerte de Jesús García García en el País Vasco. Con ello se señala nuestra cabeza a la ultraderecha española. Vaya esta denuncia por delante y para llamar a cada cual a sus responsabilidades». «Una vez más -proseguía la nota- 'Interviú' tiene que manifestar cuál es su postura y su función como órgano informativo (sic) ${ }^{(29)}$, para asegurar que la intención del reportaje en cuestión «no respondía a otro objetivo que informar sobre hechos

(26) El citado de El País no fue terminal, no tuvo más reacción que la queja de un grupo de profesionales que desmontaron su no-veracidad. ¿Qué hubiera sucedido de ser cierta la noticia? ¿Aun siendo falsa, no hay o hubo peligro para el perjudicado a través de algún incontrolado?

(27) El Día, 11.1 .80 , p. 43 / Última hora.

(28) Fecha del alzamiento fascista español contra el gobierno republicano legalmente constituido. (29) Llamamos la atención aquí sobre la «función como órgano informativo» de una publicación enteramente amarilla, en portada siempre presenta una fotografla de una mujer desnuda sin que esa presencia semana coya en mar acto

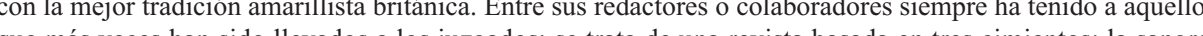
que más veces han sido llevados a los juzgados; se trata de una revista basada en tres cimientos: la sangre, el sexo y la politica, con un ideal de «noticias» politicas relacionadas con sangre y sexo. Otro detalle: fue

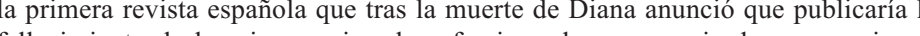
fallecimiento de la princesa si se las ofreciera alguna agencia de paparazzis. 
públicos y notorios que deben ser conocidos por la opinión española». Y más adelante: «Decir que la muerte de Jesús García García se produce a consecuencia de una denuncia de 'Interviú' es como admitir que la organización a quien se ha atribuido el atentado -la ETA- necesita de nuestros datos para conocer el País Vasco. Ridículo y mendaz. Si ha sido ETA la autora de esta muerte -y sabemos perfectamente que los caminos de la provocación son insondables como también se demostró en épocas pasadas- no puede mantenerse medio minuto que la ETA necesita a 'Interviú' para desarrollar sus actividades o acopiar información».

Los interesados podrán encontrar el texto completo en las notas del final ${ }^{(30)}$ pero llamemos la atención de algunos detalles de las líneas reproducidas:

(30) Con el título «¿Por qué contra 'Interviú’? y con un sumario que dice «Nota de la redacción de Interviú», la nota íntegra añade

«De una manera brutal, con un tono de incitación a comportamientos propios de guerra civil -nos trae «De una manera brutal, con un tono de incitacion a come jutio de 1936 - cierta prensa españla -nos trae recuerdos de las tristes fechas que antecedieron al 18 de julio de 1936- cierta prensa española nos hace práticante respona

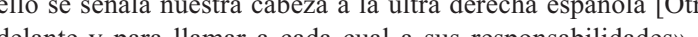
delante y para 1

«Una vez más 'Interviú' tiene que manifestar cuál es su postura y su función como órgano informativo El reportaje en el que relatamos los comportamientos de quienes desarrollaron actividades suscitadoras de violencia en el País Vasco no respondía a otro objetivo de (sic) informar sobre hechos públicos y notorios que deben ser conocidos por la opinión española. Una sociedad se perfecciona con la reflexión sobre su propia realidad. El periodismo tiene, entre otros deberes, el de suministrar datos para esa reflexión». «Creemos que en vez de pedir ahora nuestra cabeza, abiertamente y con una impudicia punible, lo que deberí haber hecho la prensa que nos ataca -y la connivencia con ella al destacar sus criterios y manipular u oculta los nuestros- era solicitar del gobierno que actuara como tal abriendo la correspondiente investigación sobre los hechos descritos por nosotros. De esa información habría salido la corrección de los excesos relatados por 'Interviú' o el castigo legal de 'Interviú', caso de haber mentido e investigado con negligencia». [Ese 'castigo legal' llegó con la sentencia contra el autor de los textos, que se exilió en Londres].

«Pero esa prensa ha referido pedir nuestra cabeza sobre la bandeja del atentado antes de contribuir a la clarificación del ambiente nacional. Sabrá esa prensa por qué. Digamos, no obstante, que si nosotros cayésemos no sería precisamente esa prensa la que abriría las ventanas del país a una luz nueva. Porque esa prensa no merece ni respeto ni audiencia. Por ahí habría que buscar otro motivo de odio hacia nosotros».

«Decir que la muerte de Jesús García García se produce como consecuencia de una denuncia de 'Interviú tado -la ETA- necesita de nuestros dato para conocer el País Vasco. Ridículo y mendaz. Si ha sido ETA la autora de esta muerte -y sabemos perfectamente que los caminos de la provocación son insondables como también se demostró en épocas pasadas- no puede mantenerse medio minuto que la ETA necesita a 'Interviú' para desarrollar sus actividades o acopiar información. Ahora va a resultar que una organización que trae de cabeza a toda la policía española ha de leer la prensa para determinar dónde se encuentra su adversario».

«Hemos dado instrucciones a nuestros abogados para que se querellen contra aquellos que nos han difamado, calumniado y ultrajado. Esperamos ahora confiadamente en la justicia, no sólo para defender nuestras vidas de profesionales del periodismo sino para proteger, sobre todo, la verdad y el derecho a tras vidas de profesionales del periodismo sino para proteger, sobre todo, la verdad y el derecho a informacion. Aprovechar una muerte oscura para arremeter contra una revista que se ha propuesto depura contamina contaminada como la nuestra, equivale a degollar la verdad por el simple, rudo y criminal procedimiento
de degollar al vocero de la misma».

«Nosotros permanecemos fieles a una línea que nos ha llevado a ser una revista entrañada con la calle. Y la calle rechaza siempre lo criminal y lo sucio. Eso se afirma incluso desde la ultraderecha. Luego apliquemos la lógica para determinar por qué somos populares». 
- Cuando hablan de la banda terrorista la califican de organización, pero sin el apelativo de terrorista;

- Cuando hablan de la desaparición de Jesús García, hablan de muerte y nunca de crimen o asesinato;

- Cuando emplean la palabra crimen lo hacen de manera ambigua y sin referencias al acontecimiento originado tras la publicación del reportaje denuncia, sino a su temor de que el síndrome aquí analizado se vuelva contra ellos.

Además, aparecen seis rasgos de todo amarillismo descubierto:

$\left.1^{\circ}\right)$ Insistir en que se mantendrán en su línea de trabajo, que dan a entender que es seria y rigurosa;

$2^{\circ}$ ) Hacer ver algunos de los valores indiscutibles del periodismo, que evidentemente no se dan en los aperiodistas, porque chocan con los fundamentos del amarillismo;

$3^{\circ}$ ) Manifestar temor porque las críticas cosechadas se vuelvan contra ellos;

$\left.4^{\circ}\right)$ Asustar conque han puesto el asunto en manos de sus abogados, para que éstos actúen contra los críticos;

$5^{\circ}$ ) Intentar desprestigiar, con fórmulas amarillas, a «los otros»: Interviu dice en su nota cosas tan fundamentalistas como «esa prensa no merece ni respeto ni audiencia»;

$6^{\circ}$ ) Asegurar, por último, que confían ciegamente en la justicia.

Con los tres puntos primeros intentarán congraciarse o convencer a sus lectores. Con los tres puntos finales lanzan una invitación subliminal a «los otros», para decirles, 'Vamos a dejarlo aquí', 'No sigamos con este asunto'(31).

En una intervención por televisión, el periodista español condenado en Nueva York por espiar telefónicamente a una joven amiga de un príncipe, dejó muy claro (punto 1) que él seguía 'haciendo periodismo' como antes, porque no había hecho nada malo y todo había sido un malentendido.

De acuerdo con la teoría del efecto I expuesto, los responsables de Interviu ponen en duda que la banda 'necesite de nuestros datos para conocer el País

«Lamentamos la muerte de Jesús García García, como la de tantos otros que han caído sin que 'Interviú hablase de ellos. A español se reduce a una revista. Ridículo y lamentable. Lo malo es que, ridículo y lamentable, sirve para español se reduce a una revista. Ridículo y lamentable. Lo malo es que, ridículo y lamentable, sirve para
incitar al crimen». [Nueva aproximación a un potencial efecto I].[Los textos entre corchetes son nuestros] (31) Hasta cinco veces en la nota emplean la voz «español» o «española». Es evidente que una revista española Hasta cinco veces en la nota emplean la voz «español»o «española». Es evidente que una revista española no precisa el empleo de esa voz, si tenemos en cuenta que todo lo que dice en un comunicado como e que nos ocupa estará referido a España... pero, ¿hasta qué punto no hay un mensaje subliminal de adulación a quienes no se sienten españoles, los integrantes de la banda terrorista, para aplicar el adjetivo cas siempre en este caso de forma pareja a estamentos criticados o puestos en evidencia?: 'cierta prensa española', 'ultraderecha española', 'la policía española', 'el problema español', 'la cuestión española'. Todo lo que se ha puesto con el calificativo de español o española se entiende igual sin el mismo adjetivo: er innecesario; se ha puesto con calzador con fines no directamente informativo sino 'aproximativos'. [El uso digamos peyorativo sólo deja de darse cuando en una sexta ocasión hablan de la gente ('la opinión española')]. 
Vasco'; 'no puede mantenerse medio minuto que la ETA necesite a Interviú para desarrollar sus actividades o acopiar información» o bien 'Ahora va a resultar que una organización que trae de cabeza a toda la policía española ha de leer la prensa para determinar dónde se encuentra su adversario'.

Hay algo verdadero en el alarde de esta gangrena de lo amarillo: no era necesario que los terroristas conocieran el problema expuesto desde sus páginas, pero ésa no es la cuestión. El asunto está en que va a ser siempre la exposición pública del asunto en la prensa el detalle final o, como hemos dicho, la «provocación informativa», para que el poder actúe y se dé a conocer por medio de un claro, rápido y contundente efecto I.

No es preciso que el poder se entere de una cuestión por su lectura en tipos de imprenta. ¿Es que acaso la justicia francesa no conocía que las investigaciones del caso de violación expuesto no avanzaban? Actuó a raíz de las denuncias de la prensa, de un cierto tipo de «provocación informativa», como primer paso de un síndrome de Buckingham, que es un cuadro comunicativo con resultados muy distintos de todo efecto I.

Sucedió lo mismo con el caso de Melilla, ¿acaso las autoridades, los militares destinados en Melilla, podrían desconocer lo que sucedía en el paso fronterizo? Lo sabían a la perfección, pero sólo será a raíz de la publicación en prensa cuando el asunto adquiere proporciones mayores y una audiencia superior. En ese momento se ven abocados los ocupantes del poder directamente afectado a tomar decisiones en pro de ofrecer una solución al caso y evitar el deterioro de su imagen, a exponerse a la propia pérdida del poder.

De igual manera, ¿la familia real inglesa tuvo que leer la prensa para ver las colas de público fuera de sus palacios?, ¿para pulsar el eco popular por la muerte de Diana?, ¿entender que su frialdad estaba siendo muy mal interpretada por el público británico?

No es así; los que están en el poder conocen todos esos detalles, entre otras cosas porque hay funcionarios cuya misión es precisamente ésa, pero no han actuado hasta entonces por su desidia o cualquier otro tipo de vicio oculto.

Sigamos con el caso que da nombre a este síndrome negativo: pocos días después de la nota de prensa comentada, vuelve a aparecer otra noticia en los periódicos sobre el mismo caso $^{(32)}$, el asesinato de otro de los dueños de bar del

(32) «Muerto, tras ser secuestrado, el dueño de un bar en Baracaldo / Es la segunda víctima entre las personas «Muerto, tras ser secuestrado, el dueño de un bar en Baracaldo / Es la segunda victima entre las personas
citadas por el reportaje de 'Interviú'». La noticia, de la agencia Efe, está fechada en Bilbao y dice textualmente [seguimos el texto publicado en el periódico El Dia, Tenerife, 24.1.80, p. 39/ Ultima hora] "Alfredo Ramos Vazquez, de 52 años de edad, casado y con dos hijos, fue muerto a tiros ayer tarde, tra haber sido secuestrado por unos encapuchados cuando se encontraba en el bar de su propiedad. El seño Ramos recibio cinco disparos en la cabeza y en el lugar de los hechos, en La Arboleda, Mnicipio de Sa Salvador del Valle, en un descampado, la policía encontró cinco casquillos de bala calibre $9 \mathrm{~mm}$. Parabellum, marca Gecco, munición utilizada habitualmente por ETA militar. 
mismo pueblo, también citado en el reportaje denuncia de Interviú, dibujado por Vinader con estas palabras: «Un dueño gallego que se divierte participando en enfrentamientos con los abertzales [nacionalistas vascos]». Tenemos las siguientes consideraciones:

1) El autor del texto, Xavier Vinader, publicó sus reportajes sin hablar con una (o varias) de las personas afectadas por la denuncia que se hacía, tal y como es canónico en todo periodismo de investigación (si la labor de Vinader se quería hacer pasar por tal), donde sus practicantes están moral, ética y profesionalmente obligados a contar con los testimonios o manifestaciones de todas las partes afectadas por su investigación.

2) De nada sirvió que el afectado dijera públicamente que nada tenía que ver con la historia facilitada desde el semanario amarillo: la provocación periodística

Poco después de las tres de la tarde, dos individuos encapuchados entraron en el bar Stadium y obligaron Poco dropietario a que les acompãara después de intimidar a la esposa, a una hija y una sobrna co a su propic

Los autores del secuestro obligaron al propietario a subir a un Chrysler, de color amarillo, donde esperab al volante un tercer individuo, también encapuchado, y se dieron a la fuga.

an llante un tercer ind recibida por teĺfono en el diari 'Egin', sobre las 5 de la tarde, comunicó que Una llá de Alfredo Ramos Vázquez se cadáver de Alfodo Ranó Vázquez se eno Avisada la policia, logro encontar el cuerpo sin vida del señor Ramos en el lugar señalado. El cadáver

Un niño, el único testigo (ladillo/epígrafe)

El único testigo que hasta el momento ha conseguido la policía es un niño de corta edad, que dijo oír cinco disparos y, casi a continuación, el ruido de los motores de dos coches que se alejaban del lugar donde posteriormente fue encontrado el cadáver.

La Policía y la Guardia Civil montaron inmediatamente controles en carretera para tratar de detener a los autores del hecho, aunque el niño no pudo aportar las características de los coches, ya que «no les prestó atención».

Alfredo Ramos Vázquez, natural de Borrajeiros (Pontevedra), regentaba desde hace 18 años el bar Stadium, de la localidad vizcaína de Baracaldo.

En un reportaje de la revista 'Interviú' sobre «la ultraderecha vasca» se citaba al propietario de este ba como «un dueño gallego que se divierte participando en enfrentamientos con los abertzales». [Lo que va entre comillas aparece en negritas en el periódico].

En este mismo reportaje también era citado Jesús García García, muerto el pasado 5 de enero en atentado cuando se encontraba en el interior de su bar.

Alfredo Ramos Vázquez, después de conocer la muerte de Jesús García y de que su nombre aparecía en el reportaje de 'Interviú', contó a un periodista del diario 'La Gaceta del Norte', con el que, acompañado de su mujer y dos hijas, se entrevistó durante más de una hora, los perjuicios que le había supuesto la aparición de su nombre en aquel reportaje.

Por otra parte, el señor Ramos, el pasado día 8 envió una carta a varios medios de comunicación del País Vasco en la que desmentía toda la información de 'Interviú' sobre su persona

«Con esta manifestación», terminaba Alfredo Ramos la carta, refiriéndose a la información del citado semanario, «vertida de forma incalificable, se ha atentado contra mi dignidad personal, mi honradez y $\mathrm{m}$ negocio, cuando soy en todo punto inocente de todo cuanto se me imputa» [En el diario, lo entrecomillado va en negritas].

Ese mismo día una carta avalada por 200 firmas de baracaldenses habituales de los bares citados en 'Interviú' fue publicada en los medios de información. En la misma se estimabn inexactas las informaciones del

«A vosotras no os va a pasar nada» (ladillo/epígrafe) 
estaba lanzada desde Interviú y el poder etarra había actuado mecánicamente, de acuerdo con todos los puntos de un efecto I. Como una batidora cuando recibe corriente.

3) Tampoco sirvió de nada que 200 vecinos de Baracaldo, asiduos a los bares denunciados, firmaran igualmente un escrito (y lo publicaran), en el que aseguraban su condición de parroquianos y que estimaban inexactas las informaciones del semanario: el efecto I no se para en chiquitas.

4) Este tipo de «excusas» no sirve a un poder ilegal puesto en evidencia: aceptarlas se podría interpretar en los ambientes de los proscritos como debilidad del mando, de manera que no bajan la guardia ni corren el riesgo de ver lesionada su autoridad. Lo más práctico era mantenerse firmes, acabar con el adversario, como los llama la primera nota de la empresa editorial propiedad del empresario Asensio.

El comunicado en esta segunda ocasión es mucho más corto y comedido, útil para que no se dijera que callaron tras el segundo atentado terrorista. En esta nota ya califican de asesinato la muerte habida, pero acaban con un mensaje tan pueril como poco creíble: dicen que esperan «poseer datos fiables sobre la autoría del crimen, para hacer una nueva declaración si fuera necesario». La primera pregunta que se origina es ésta: si Interviú nada tenía que ver con los atentados, ¿qué necesidad tenía de lanzar un comunicado en que lamentaba lo ocurrido? ¿Hace tal cosa Interviú después de todo atentado, dentro o fuera del País Vasco, con autoría de ETA o de cualquier otro grupo? No, porque estamos ante un atentado previsto y cantado, fruto del efecto I aquí definido.

Hubo dos noticias más de aquel caso: a finales de enero ${ }^{(33)}$ cerró otro de los bares citados en la revista. La agencia Efe señaló que su propietario fue amenazado y que recibió el mensaje de que él sería el próximo. También que a la salida del reportaje viajó a Barcelona «para entrevistarse con directivos de Interviú». La

«Ay, mi familia; ay, mi familia», dijo Alfredo Ramos en el momento en que dos encapuchados, armado con pistolas, se lo llevaban del bar de su propiedad, ha declarado a 'Efe' una hija del señor Ramos. Por su parte, los encapuchados, según ésta, dijeron antes de marcharse.

«Tranquilas, a vosotras no os va a pasar nada».

En el momento del secuestro, se encontraban en el comedor del citado bar el matrimonio, y en la barra una hija de ambas y una sobrina.

La información cierra con este ladillo:

Nota de 'Interviú'

y este texto:

En relación con este atentado, la dirección de la revista 'Interviú' hizo público un comunicado del atentado (sic):

«Conocida la noticia del asesinato de Alfredo Ramos Vázquez, dueño del bar Stadium, y que aparecía citado en un reportaje de 'Interviú' sobre actividades de la ultraderecha en el País Vasco, la dirección de esta revista hace constar su repulsa por esta nueva acción de violencia, esperando poseer datos fiables sobre la autorí hace constar su repulsa por esta nueva acción de violencia, esperando poseer datos
del crimen para hacer una nueva declaración si fuera necesario», dice el escrito.

(33) Noticia aparecida en El Día el 31.1.80, p. 39 / Ultima hora. 
huida del lugar es, entonces, una de las formas de aplacar la fase terminal de un efecto I: ya se fue el adversario, ya no hay enemigo. Así ha sucedido con tantos periodistas colombianos, quienes han tenido que exiliarse para evitar un efecto I del narcotráfico, de los paramilitares o de la guerrilla, o sacar a sus hijos del país para evitar un efecto I sobre sus descendientes, cuando no les ha afectado a otros miembros de su familia.

La segunda noticia ${ }^{(34)}$ se refería a las amenazas recibidas en la revista amarilla y al asalto habido en el domicilio del autor de aquellos textos de denuncia. Para entonces, el reportero llevaba varios meses fuera de España, como huido de la justicia, que lo había juzgado y condenado.

Como conclusión de este apartado que hemos llamado efecto I parece afianzarse la hipótesis y la práctica de que todo poder reacciona ante la publicación de cualquier noticia si el texto actúa como estímulo informativo que erosiona la imagen o pone en evidencia al poder cuestionado, sea lícito o ilícito, se atenga ese texto o no a los cánones de la profesionalidad periodística. De no hacerlo, su imagen se deteriorará y, con ello, se pondrá en cuestión su propia estancia en el poder. En estos casos, el poder siempre optará por actuar y acallar cualquier tipo de críticas, información, denuncia o mera sospecha de que lo haga tambalear en su situación de hegemonía.

En los casos de un hegemón fuera de la ley, éste queda virtualmente obligado a reaccionar vivamente ante un provocativo texto aparecido en prensa, por haberse hecho público y llegar potencialmente a todos. La responsabilidad del periodista está fuera de toda duda, la tiene, de ahí la importancia de conocer el síndrome información-reacción (en los casos de resultados positivos, pero también y sobre todo en los previos a la presentación de un efecto I), para calibrar de antemano los posibles resultados y su consecuente responsabilidad.

Veamos otro ejemplo de aparente efecto I:

En el verano de 1997, la banda etarra tenía a dos ciudadanos secuestrados, largo tiempo desprovistos de libertad. Un buen día, la Guardia Civil descubrió el inhumano zulo donde se encontraba preso sin condena uno de los secuestrados y prácticamente a la misma hora apareció liberada la otra persona. Sobre todo la liberación de quien se encontraba en el zulo produjo una fuerte conmoción social, por el larguísimo tiempo de cautiverio injusto e irracional, como por tratarse de un humilde funcionario, por el cual no iban a solicitar, al menos, recibir, rescate alguno. Además, las imágenes de su liberación mostraban a un ser hundido, enflaquecido, con una barba larga e hirsuta.

La euforia de la mayoría de los medios de información fue desproporcionada e ingenua: no parecían conocer la teoría del efecto I. Lo sucedido después fue fácil de interpretar: la banda terrorista había recibido uno de los mayores golpes

(34) Noticia aparecida en El Día el 6.6.80, p. 42 / Ultima hora. 
asestados en su terrible historia y en su 'propio territorio'; los guardias civiles aparecían como los héroes. Si ETA no actuaba y si no lo hacía rápido, pero muy pronto y de forma radical y contundente, la imagen de los líderes terroristas se hubiera disuelto en poco tiempo. Por eso actuó ETA y puso en marcha un nuevo episodio terminal de efecto I: secuestró a un joven concejal del partido en el poder de un pequeño pueblo del País Vasco y exigió a cambio algo aparentemente imposible de conceder por el gobierno. No aparecerían como sanguinarios sino como patriotas que pedían una gracia en favor de sus presos a cambio de la liberación del nuevo secuestrado, de forma que no les iba a quedar más remedio que cumplir con su amenaza: lo matarían en 48 horas si el gobierno no trasladaba a cárceles del País Vasco a todos los terroristas presos en presidios de fuera del territorio vasco.

Aquí aparecía un nuevo estadio del síndrome mortal que analizamos: el previo anuncio del día y hora de la muerte de un inocente elegido al azar, a modo de las 'pescas milagrosas' de la guerrilla colombiana. Este nuevo aspecto puesto al descubierto llena de emoción amarga al público y entre la opinión de la calle nace el sentimiento absoluto de impotencia, de que nada podemos hacer, de que pasan los minutos y se acerca la hora del asesinato previsto y anunciado en letras de imprenta, una nueva muerte irracional, con reflejo mediático (¿era de lo que se trataba?).

Es igualmente cierto que mientras se acerca la hora del asesinato, los medios colaborarán a caldear el sentimiento generalizado de nerviosismo e impotencia (y suben sus ventas), pues el público lo más que puede hacer es consumir periódicos y transformarse en audiencia de los que miden sus índices para cobrar más suculentas facturas a los anunciantes. Por eso, el propio ministro del Interior, Jaime Mayor Oreja, insistía en no echar las campanas al vuelo cuando la liberación del funcionario de prisiones.

La conclusión del segundo efecto I estudiado es ver cómo la generalidad de los medios, sin darse cuenta del error, pueden ser los autores de una provocación informativa genérica a un poder ilegal, de manera que, de acuerdo con el efecto I, éste se ve obligado por las circunstancias a golpear a la misma sociedad que se ve refrescada por las noticias tan optimistas de los medios que ponen las bases de un impresionante efecto I, como siempre son estas formas de respuesta reaccionaria.

En ocasiones, el síndrome I se ve en los medios, en su inicio: la situación queda expuesta y el protagonista no deseado permanece con los nervios alterados, como aquellos propietarios de bares que murieron o como el que hubo de cambiar de domicilio, con una vida amenazada, esté o no la decisión tomada. Este protagonista comprobará que su vida ya no será igual, donde quiera que se encuentre.

Veamos un caso más reciente: en marzo de 1999, la policía española encontró una serie de informes en poder de un detenido por aparente colaboración con la ETA; entre otros detalles, había alusiones al «jefe de psicólogos» de la 
policía vasca. Mientras unos diarios ( $A b c$ y $E l M u n d o$ ) silenciaron el nombre que se indicaba, el diario El País (edición del 9 de marzo, página 20) publicaba nombre y apellidos del «jefe de psicólogos». El pecado grave cometido por el diario madrileño en este inicio de probable efecto I (espero equivocarme) fue no confirmar con el interesado si de verdad trabajaba para la policía, para verificar una fuente como la de un informe privado de un detenido por colaboración terrorista, que no sé hasta qué punto puede ser admitida como fuente solvente y no contrastable por un periódico serio y de rigor, de calidad, de referencia; está claro que no es una fuente en el sentido clásico y admisible como tal. En segundo lugar, el pecado de no comprobar si realmente la policía vasca dispone de un equipo de psicólogos, con un jefe al frente; en tercero, sabiendo que se trata de un catedrático de universidad, contrastar si se encuentra en régimen de tiempo parcial o de tiempo completo. Eso sería periodismo de investigación, costoso, que reclama tiempo. Si trabaja para un organismo oficial, tal es el caso de hacerlo para la policía vasca, sólo podría estar en la Universidad del País Vasco a tiempo parcial, pero en la nota de réplica del afectado deja claro que se encuentra en régimen de tiempo completo. Son muchos errores en un diario serio. El propio perjudicado advierte del resultado posible del efecto I que estamos analizando. Dice en su réplica (El Pais, 14.3.99, p. 13):

«Infundios de este tipo han estado en el origen de conductas violentas contra víctimas inocentes en el País Vasco» (punto 1 de su nota);

«... señalar mi nombre contribuye a una victimización secundaria y a ponerme en el punto de mira de los sectores que siguen practicando la violencia en el País Vasco» (punto 2).prestada nomenclatura cínico-militar) en casos como el apuntado, como el de todo efecto I, es de una envergadura tan grave que esta reacción vista a la provocación mediática debe ser conocida por todo periodista, para evitar su colaboración en actos criminales, que sin su intervención no se van a dar y están «en el origen de conductas violentas contra víctimas inocentes». Inocentes o no, personas convertidas en víctimas por la mediación de órganos de comunicación social, que en un momento determinado y por una actuación no profesional habrán colaborado con el criminal, se han puesto también ellos fuera de la ley informativa.

\section{El síndrome de Washington}

Tenemos un tercer caso de respuesta del poder a los estímulos, en este caso provocaciones desde el papel prensa, en una suerte de mezcla de síndrome B y efecto I. El síndrome $\mathrm{W}$ se da en un poder legítimo (como en el síndrome B) pero origina una respuesta negativa (como en el efecto I). Es una acción mixta, con lo peor de ambas.

Al tratarse de un poder legítimo quien reacciona ante la provocación, será muy difícil constatar estos casos cuando son contemporáneos, aunque pueden 
vislumbrarse en ocasiones. Es el ejemplo de la prensa chilena de derechas que en 1998 y 1999 presionaba desde sus páginas para que el gobierno rompiera relaciones diplomáticas con Londres y Madrid, con motivo de la detención del antiguo dictador chileno.

Pero a lo largo de la historia de la prensa, sobre todo en episodios de sensacionalismo, se pueden encontrar algunos casos nítidos donde se ve claramente la provocación como recurso periodístico. Durante el calentamiento artificial y desde la prensa del empeoramiento de las relaciones hispano-estadounidenses en 1898, con Cuba al fondo, encontramos serios ejemplos de provocación sobre Washington -de ahí el nombre de este síndrome- desde los medios campeones de la prensa amarilla del momento. Veamos algunos ejemplos:

- La revista Judge publicó en su número del 19.X.1895 una ilustración, obra de la ficción del dibujante Víctor Guillam, que se enmarca en un síndrome de Washington, de presionar y poner en evidencia al gobierno de Washington para que de una vez y como deseaba la prensa amarilla, ansiosa de subir sus ventas, tomara cartas en el asunto de Cuba. Dice Julián Companys Monclús: «Su fin sería apremiar a la opinión pública norteamericana, y en especial al gobierno estadounidense, a una intervención militar en Cuba a favor de los rebeldes» ${ }^{(35)}$. En esa ilustración aparece una figura femenina que representa a Estados Unidos en estado durmiente -o sea, el gobierno de Washington-, mientras enfrente de ella y en otra viñeta un español realiza tropelías sobre una mujer cubana; a su lado, varias figuras históricas y populares incitan a la actuación norteamericana.

- En otra ilustración del mismo tipo y semejante intención, parecida en la edición del 6.II.1897 se vuelven a ver en un lado lo que sucedía en Cuba según la prensa amarilla de EE.UU. y a la derecha la pasividad de Washington, aquí con la figura del tío Sam atado de pies y manos y con los ojos vendados, para no ver lo que sucedía ni poder actuar. Según Companys (1998: 70): «Las ligaduras de los pies del personaje llevan escrito el nombre del culpable que le impide la libertad de movimientos para actuar: la administración demócrata del presidente Cleveland» y se trataba de «Toda una incitación por parte de la revista hacia sus lectores, ya que los Estados Unidos disponían de los medios necesarios para ello, según atestiguan los cañones y el barco del lado derecho de la ilustración».

- Para acabar, un tercer ejemplo. En la misma revista, Judge, del 26 de marzo de 1898, aparece una estampa del mismo ilustrador con una nueva provocación. «Al presidente McKinley (Companys, 1998: 72) el artista lo ha convertido en un Hamlet y, al igual que el príncipe de Dinamarca, está sumido en un mar de dudas. Pero es que, a su vez, su dilema es mayor puesto que se ve sometido a fuertes presiones contrapuestas». En la imagen que se reproduce se ve al presiden-

(35) Julián Companys Monclús, 1998, La prensa amarilla norteamericana en 1898. Editorial Sílex, Madrid, 115 páginas, ISBN: 84-7737-067-2, página 67. 
te vestido de gala, mientras los personajes de la zona izquierda de la imagen le reclaman su atención. «Entretanto, McKinley sigue sin tomar una decisión» (Ib.). En el dibujo, a la derecha del presidente, aparecen unos personajes enanos pero vestidos con los mejores trajes, «partidarios de mantener la paz a toda costa (Ib., p. 73). La mezquindad de las pretensiones de estos últimos se pone de manifiesto en un cartel que hay en el suelo: 'No nos importen los marineros del Maine, miradlo desde un punto de vista económico. No entorpezcáis con la guerra el comercio de Nueva Inglaterra' (o sea, Estados Unidos)».

Esto último -la defensa de los intereses materiales- se ha manifestado en los primeros compases de la crisis abierta entre España y Chile tras la detención del dictador chileno. Así, el ministro español de Asuntos Exteriores, Abel Matutes, ha dejado muy claro que son muchos y muy importantes las inversiones españolas en Chile, de ahí que ha de actuar con mucha prudencia ${ }^{(36)}$, dando a entender que no sería tan prudente si no hubiera inversiones (dos varas de medir su actuación) o que la actitud del gobierno español podría enfriarse en el asunto Pinochet si éste caso sigue adelante. [La actitud del gobierno de Madrid quedará más clara -pero en el mismo sentido- cuando trata de que el partido de la oposición no arme mucha gresca con el proyecto de quitar el caso Pinochet a la justicia española, según los deseos del gobierno chileno ${ }^{(37)}$.].

En definitiva, lo que implica un síndrome $\mathrm{W}$ es la intervención de un gobierno en asuntos que sin la provocación desde la prensa, amarilla o no, tal vez no se hubiera realizado. Como finaliza el citado autor (Ib., 107): se trata de «(...) la actuación de algunos políticos y militares, con miras expansionistas, y la actitud de la prensa en busca de ganancias materiales. Sin embargo, fueron las publicaciones estadounidenses las que contribuyeron, de manera decisiva, en crear ese carácter popular que rodeó al conflicto, pero la responsabilidad del inicio de la contienda recae en la administración norteamericana».

\section{Conclusión}

Como resumen de lo que hemos analizado hasta aquí, tenemos:

$\left.1^{\circ}\right)$ El poder, del tipo que sea, reacciona cuando se divulgan estímulos informativos capaces de dañar su imagen y de ponerlo en evidencia ante los votantes como malos gestores y de tener posturas despreciativas hacia los intereses públicos.

(36) «Matutes [nombre del ministro] aconseja 'prudencia', porque España cuenta con 'importantes inversiones' en Chile» (La Gaceta de Canarias, 27.XI.98, p. 29): «Abel Matutes aconseja actuar con la máxima prudencia, porque 'hay inversiones por valor de un billón de pesetas'. Como ministro de Asuntos Exteriores, 'sería un irresponsable si no tuviera en cuenta estas cosas', proclama».

(37) Matutes pide apoyo al PSOE para un arreglo sobre Pinochet / El Gobierno es proclive a la propuesta de Chile de un arbitraje 'amistoso' (El Pais, 1.VIII.99, p. 1).

*) Un resumen de este texto se pronunció como conferencia de clausura de la II Bienal de la Comunicación, celebrada en la Universidad de Cartagena de Indias (Colombia), en mayo de 1999. 
$2^{\circ}$ ) Hay una reacción positiva -que llamamos síndrome B o de Buckinghamque consiste en enmendar la situación que ha originado la corriente crítica publicada en los medios.

$3^{\circ}$ ) Hay un tipo de reacción negativa -que llamamos efecto I-, que es la que da un tipo de poder ilícito que no dejará pasar la oportunidad presentada para reafirmarse en su ocupación de ese poder. Un potencial efecto I abierto a partir de la intervención informativa de un medio implica una muy grave responsabilidad de éste ante la reacción violenta que se pueda producir a partir de su provocación informativa. Peor, si lo que se afirma no se ha contrastado y verificado entre las partes que aparecen en el texto, en busca de la sorpresa informativa.

$\left.4^{\circ}\right)$ El efecto I se manifestará aunque la jerarquía afectada tuviera noticia de la situación comunicada por los medios, porque no podrá tolerar que su imagen se debilite si se mantuviera al margen del estímulo informativo emitido.

$5^{\circ}$ ) Es muy de lamentar que un medio por motivos empresariales llegue al punto de dar una nota sesgada y sirva los preámbulos de un efecto I. Peor, si cabe, si los motivos empresariales no son los del propio medio, sino de otros negocios de su propietario.

$\left.6^{\circ}\right)$ Existe otra figura, mezcla de síndrome b y de efecto I, cuando el poder provocado desde la prensa es un poder legítimo que se ve provocado a tomar decisiones que de no terciar ese incitamiento desde los medios las tomaría con mayor frialdad y reflexión o no las tomaría. Le damos el nombre de síndrome $\mathrm{W}$, porque fue en Washington y durante los preámbulos de la guerra hispano-norteamericana donde se vieron varias y contundentes muestras de este tipo de presión ilegítima desde medios informativos sobre el poder legítimo de los Estados Unidos.

$\left.7^{\circ}\right)$ Los profesionales de la información han de ser conscientes de los tipos de síndrome señalados: el primero, para originar situaciones más acordes con la democracia social, y el segundo y el tercero para evitar la ruptura ética que da paso desde los media a todo efecto I o síndrome $\mathrm{W}$, sea terminal o no. 